\title{
Follicular Lymphoma with Marginal Zone Differentiation: Microdissection Demonstrates the $t(14 ; 18)$ in Both the Follicular and Marginal Zone Components
}

Subramanian Yegappan, M.D., Bertram Schnitzer, M.D., Eric D. Hsi, M.D.

Department of Clinical Pathology, Cleveland Clinic Foundation (SY, EDH), Cleveland, Ohio; and

Department of Pathology, University of Michigan Medical School, Ann Arbor, Michigan (BS)

On occasion, follicle center lymphomas (FCL) may contain a marginal-zone (MZ) component in which the interfollicular lymphoid cells take on an MZ cell morphology. In the past, these have been termed composite lymphomas. However, recent studies suggest that the two components are clonally related. It is unknown whether the bcl-2 translocation present in most FCLs is present in the cells that demonstrate MZ cell morphology. We have identified three cases of low-grade FCL with a MZ component suitable for laser capture microdissection (LCM) of the two components. Cases were immunophenotyped in paraffin section with antibodies to CD10, CD20, bcl-2, and bcl-6. LCM was done to isolate cells from each component. Polymerase chain reaction for $t(14 ; 18)$ using primers to the major breakpoint region was performed on DNA extracts. The sensitivity of the PCR assay was decreased to $5 \%-10 \%$ follicle center cells in a background of reactive tonsil cells. All three cases showed different phenotypes in each component. The FCL component was positive for all four of the above markers, whereas the MZ component expressed only CD20 and bcl-2. Both components showed $t(14 ; 18)$ amplicons of identical size, with the MZ component signal being stronger than the $5 \%-10 \%$ sensitivity control, suggesting that the signal was not from rare, contaminating FCL cells. These results confirm that both components are clonally related and support the theory that these are indeed FCLs with MZ differentiation (that retain the $t(14 ; 18)$ ) rather than the reverse, MZ lymphoma with follicle center differentiation.

Copyright (C) 2001 by The United States and Canadian Academy of Pathology, Inc.

VOL. 14, NO. 3, P. 191, 2001 Printed in the U.S.A.

Date of acceptance: December 4, 2000.

Address reprint requests to: E.D. Hsi, M.D., Department of Clinical Pathology, L-11, Cleveland Clinic Foundation, 9500 Euclid Avenue, Cleveland, OH 44195; e-mail: hsie@ccf.org; fax: 216-444-4414.
KEY WORDS: Bcl-2, Composite lymphoma, Follicle center lymphoma, Marginal zone lymphoma, Microdissection, PCR.

Mod Pathol 2001;14(3):191-196

Follicle center lymphomas (FCLs) exhibit a follicular architecture consisting of small cleaved and large noncleaved cells (centrocytes and centroblasts; 1); however, occasionally, some lymphomas can show morphological features of both FCL and marginal-zone lymphoma (MZL). These lymphomas have been called composite lymphomas (2). Both components are considered neoplastic, and light-chain identity between the FCL and MZL components has been established (2-4). In a recent study, monocytoid B cells (MBC) were present at least to some degree in $23 \%$ of FCL, with $9 \%$ exhibiting a prominent extrafollicular component (5). It has been suggested that such cases have a poorer prognosis than standard FCL. Thus, it appears that there is a relationship between the FCL and MZL components. Although bcl-2 gene rearrangement has been demonstrated in these lymphomas by karyotyping (6), polymerase chain reaction (PCR; 2 ), and Southern blotting (4), it is difficult to determine with certainty the cellular origin of this rearrangement. We used laser capture microdissection (LCM) in three cases of FCL with extensive marginal-zone component to determine whether the bcl-2 gene rearrangement is present in both components. The finding of $t(14 ; 18)$ in both components would support the contention that these lymphomas should best be regarded as FCLs in which the MZL component represents marginalzone differentiation, rather than independent processes or even follicular differentiation of a MZL.

\section{MATERIALS AND METHODS}

Three cases of FCL with marginal-zone/MBC components suitable for microdissection were se- 
lected from the pathology files of the University of Michigan (Patient 1) and the Cleveland Clinic Foundation (Patients 2 and 3 ) on the basis of being FCLs with the $t(14 ; 18)$ and an extensive marginalzone component easily identifiable at low magnification on hematoxylin and eosin (H\&E)-stained sections. The marginal-zone component generally occupied almost the entire interfollicular area. Formalin-fixed, paraffin-embedded material was available in each case. Immunohistochemistry for polyclonal CD3 (Zymed, prediluted, South San Francisco, CA), CD10 (Novocastra, Newcastle-onTyne, United Kingdom; 1:5), CD20 (DAKO, Carpinteria, CA, 1:50), bcl-2 (Ventana, Tucson, AZ, prediluted), bcl-6 (SantaCruz Biotechnology, Santa Cruz, CA, 1:20), and MIB-1 (Novocastra, 1:10) was performed on a Ventana ES automated immunostainer using methods published elsewhere (7).

LCM was performed using a PixCell II (Arcturus, Santa Clara, CA) on uncharged, nonheated, H\&Estained slides without coverslips. For the FCL and marginal-zone components, 1500 captures each were performed with a $15-30-\mu \mathrm{m}$-diameter laser spot. For the $1 \%, 5 \%$ and $10 \%$ sensitivity control, 15 , 75 , and 150 captures of the FCL components were combined on the same LCM cap with 1485, 1425, and 1350 captures of reactive follicles (from surgically removed hyperplastic tonsils), respectively. LCM parameters were as follows: $15-30-\mu \mathrm{m}-$ diameter beam, 30-40-millisecond pulse, and $30-50 \mathrm{~mW}$ of power. DNA extraction buffer was 10 mм Tris- 1 mм EDTA, $\mathrm{pH}$ 8.0, with $0.4 \%$ proteinase $\mathrm{K}$ (Gibco-BRL, Bethesda, MD), with overnight incubation at $37^{\circ} \mathrm{C}$. After heat inactivation at $95^{\circ} \mathrm{C}$ for 10 minutes, PCR for the $t(14 ; 18)$ was done using major breakpoint region primers for 35 cycles (7). This cycle number is lower than the routine 43 cycles (Cleveland Clinic Molecular Pathology Laboratory protocol) to reduce sensitivity. This control was done to ensure that the PCR signal was from a substantial number (more than $5 \%-10 \%$ ) of the cells in the sample. Thus, if the marginal-zone component was positive for $t(14 ; 18)$, it would likely be due to those cells rather than to a rare contaminating neoplastic follicle center cell. Positive control for $t(14 ; 18)$ consisted of a previously positive FCL. $\beta$-globin served as the control for amplifiable DNA. Controls amplified appropriately. Whole-tissue PCR for bcl-2 by major breakpoint region primers was also done using standard methods (7).

\section{RESULTS}

\section{Clinical}

Patient 1 was a 49-year-old man; Patients 2 and 3 were women aged 38 and 60 years. All three lymph node biopsies were from the groin area and were the initial sites of presentation. No patient had a prior history of lymphoma.

\section{Histopathology}

In H\&E sections, there was a follicular architecture at low magnification. The follicles were composed of small, cleaved and occasional large, noncleaved cells. The former predominated, and the follicular components were classified as FCL, Grade I of III, in each case, according to the criteria of Mann and Berard (8). Surrounding almost all of the follicles were cells with round to slightly irregular nuclei and moderate amounts of clear cytoplasm, imparting a pale appearance at low magnification. These were mostly small cells with a few larger nucleolated cells and resembled marginal-zone cells. Intrafollicular marginal-zone cells or follicular colonization was not observed. These marginalzone cells extended into the interfollicular areas extensively, such that virtually the entire interfollicular zone consisted of these cells (Fig. 1). Diffuse areas of FCL were absent.

\section{Immunohistochemistry}

The follicle center cells within the follicular structures were positive for CD20, bcl-2, bcl-6, and CD10. In contrast, the marginal-zone cells were positive for CD20 and bcl-2 but were completely negative for bcl-6 and CD10. Both components showed occasional MIB-1-positive cells. Bcl-2 staining was of equal intensity in both components. Residual CD3 + T-cells were present within the follicles and in the interfollicular areas but were greatly outnumbered by B cells. An example of the immunohistochemical staining pattern is shown in Figure 2.

\section{Polymerase Chain Reaction}

Using DNA extracts from whole-tissue PCR, the bcl-2 gene rearrangement was detected in all three cases (Fig. 3). PCR products were similar in size, roughly $140-180$ base pairs. PCR of DNA extracts from the microdissected FCL and marginal-zone components demonstrated a band of equal size in each of the three cases, consistent with an identical sequence (clone). Efficiency of obtaining amplifiable PCR products was low because each case was attempted a minimum of two times and up to four times, probably a result of the use of fixed tissue and the requirement of H\&E-stained sections for optimal morphology (hematoxylin is known to inhibit PCR in LCM; 9). Figure 4 demonstrates Case 1, in which each component is shown next to simultaneous sensitivity amplification of $10 \%$ and $1 \%$ of microdissected FCL component diluted with $90 \%$ 

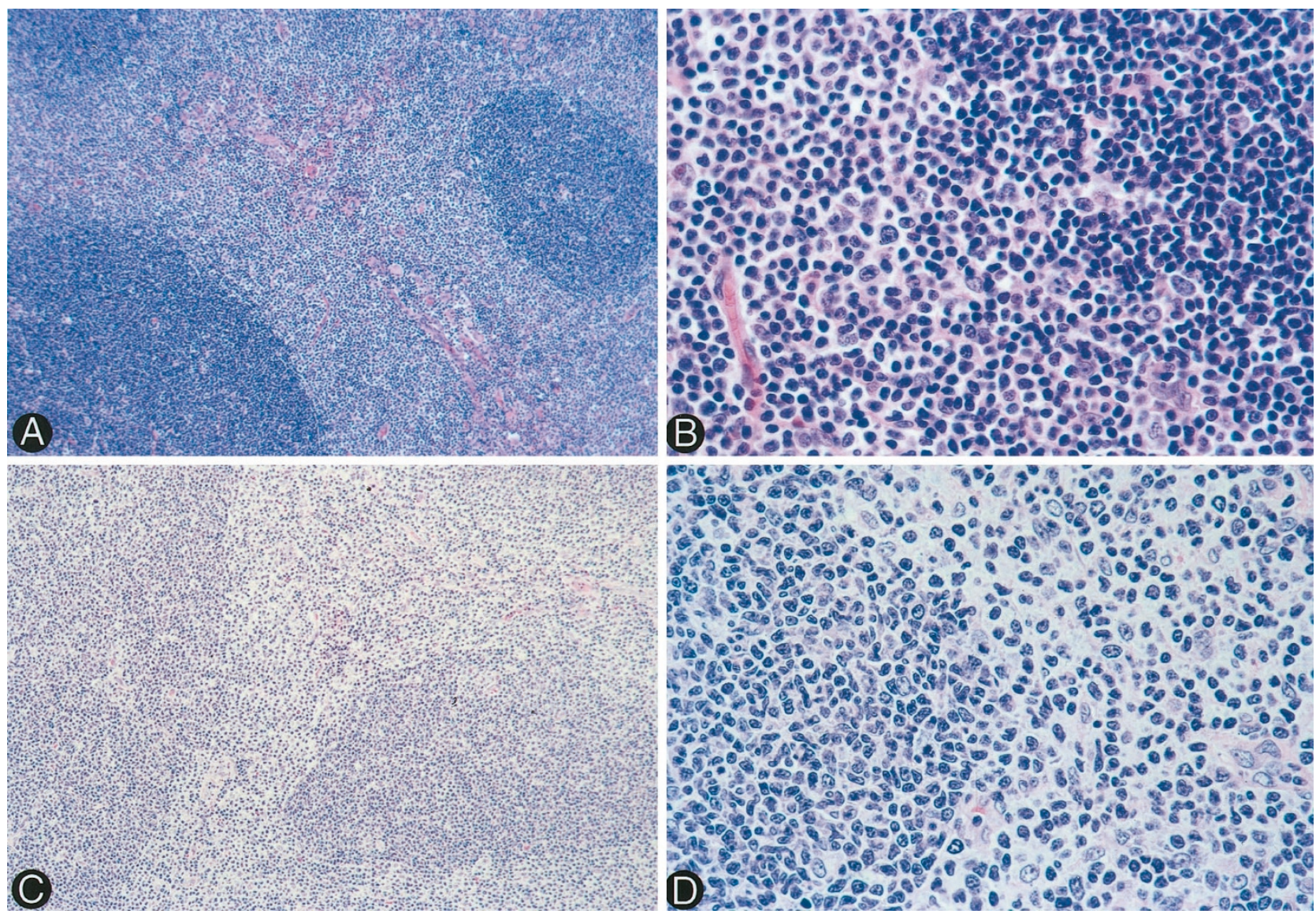

FIGURE 1. A and C illustrate low-magnification appearance of Cases 1 and 3, respectively, demonstrating follicle center lymphoma with extensive marginal zone differentiation. In these cases, the marginal-zone component is paler than the follicle centers and fills the interfollicular area, making these cases ideal for microdissection studies. Panels $\mathbf{B}$ and $\mathbf{D}$ show the high-magnification appearance of the marginal-zone cells in Cases 1 and 3, respectively. The cells are small with moderate amounts of cytoplasm. Occasional larger cells with open chromatin are also present. Follicle center cells are shown in contrast in each panel (right upper corner in B and left side in D).

and $99 \%$ microdissected hyperplastic tonsillar tissue. The $10 \%$ sensitivity control product was of lesser intensity (only faintly present band) than the marginal-zone component product. $\beta$-globin was appropriately amplified in the $10 \%$ and $1 \%$ lanes and was of equal strong intensity. Figure 5 shows follicular and marginal-zone component $t(14 ; 18)$ PCR results in Cases 2 and 3. In each case, a faint band is seen at the $5 \%$ level, with much stronger bands seen in the follicular and marginal-zone components. Figure 6 shows an example of laser microdissection used for PCR.

\section{DISCUSSION}

Lymphomas with distinct FCL and MZL morphologies have recently been recognized. A histogenetic relationship between the two components was first proposed by Sheibani et al. (10) In subsequent studies, an FCL component has been reported in $14 \%-44 \%(11,12)$ of MZL. Conversely, a prominent proliferation of extrafollicular MBC has been reported in $9 \%$ of FCL (5). Thus, FCL with at least some degree of marginal-zone component is not uncommon. A common clonal origin is suggested by identical light-chain restriction in these cases (2). We sought to examine a small number of cases with extensive FCL and marginal-zone components that would lend themselves to easy LCM separation of the two components to determine whether the $t(14 ; 18)$ typically seen in FCL was also present in the marginal-zone component, thus supporting the theory that these lymphomas represent FCL in which there is a degree of marginal-zone differentiation in the interfollicular areas.

The status of bcl-2 protein expression and gene rearrangement has been used to study the relationship between these components. Bcl-2 protein has been detected by immunohistochemistry in both FCL and marginal-zone components, though with a weaker intensity in the marginal-zone component (2-4). Likewise, the $t(14 ; 18)$ has been demonstrated in these lymphomas $(4,6)$. However, specific localization of the cells containing the $t(14 ; 18)$ translocation has not been ascertained. In both components, identical light-chain restriction has been reported (2-4), suggesting a clonal link, but CD10, a marker indicating follicle center cell origin, was de- 

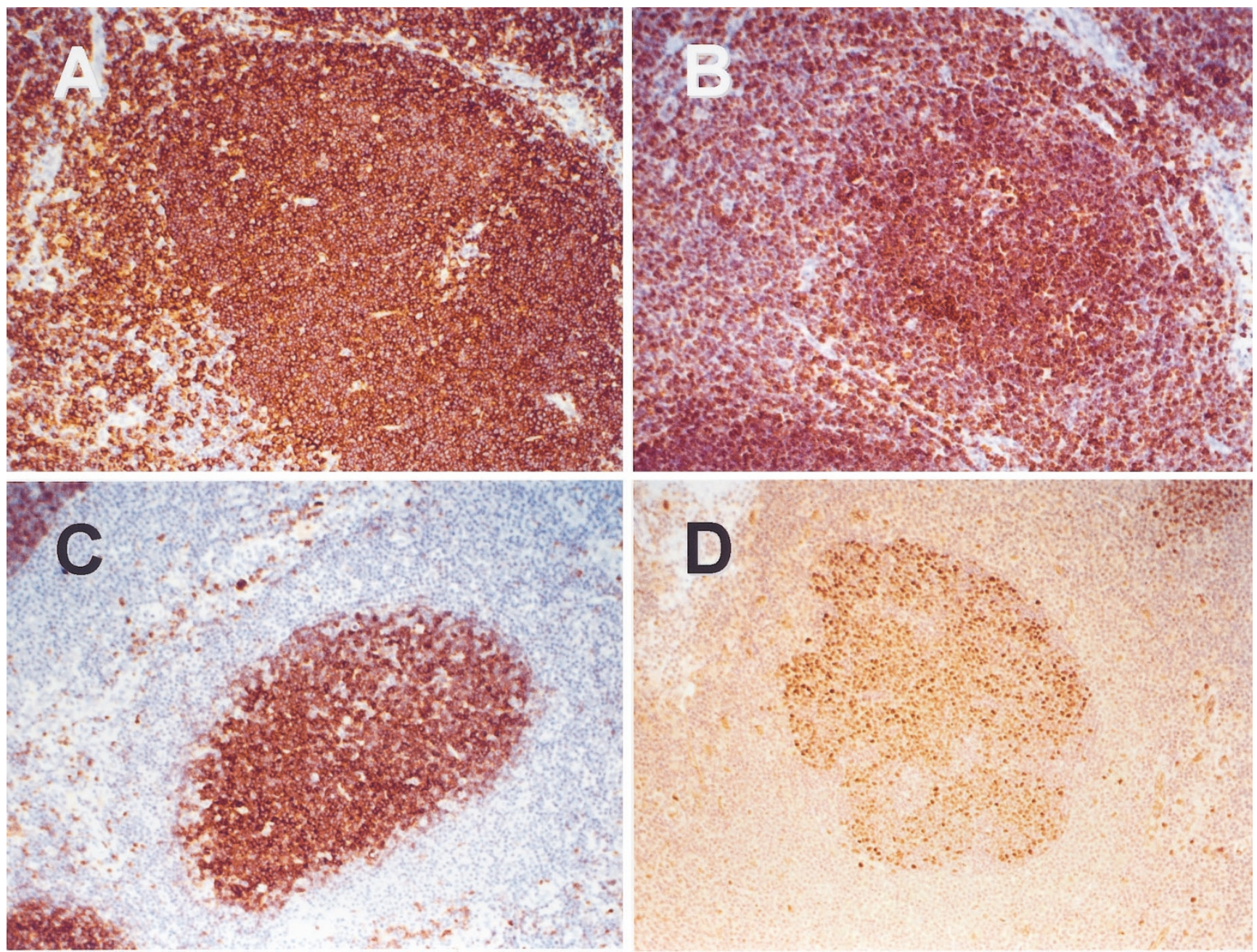

FIGURE 2. Immunohistochemistry of Case 1 showing that the great majority of cells both within and outside the follicles are B cells expressing CD20 (A) and bcl-2 protein (B). The follicular component also expresses CD10 (C) and bcl-6 (D), whereas the marginal-zone component lacks these antigens.
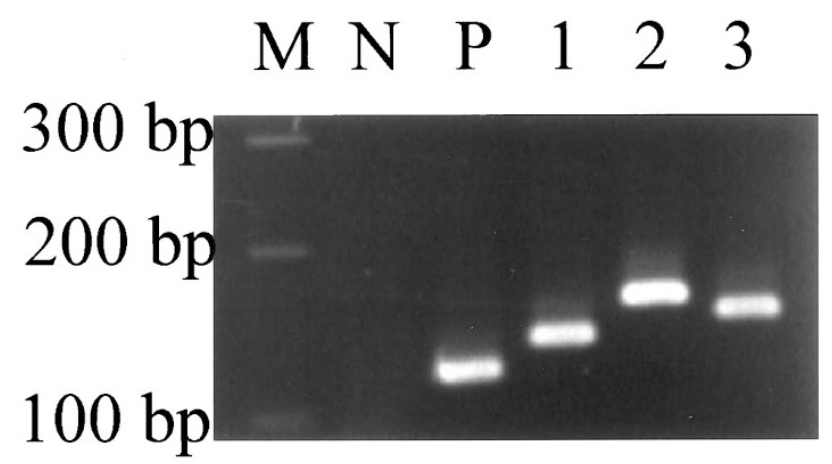

FIGURE 3. Polymerase chain reaction for $t(14 ; 18)$ using major breakpoint region primers from DNA extracts of whole tissue. Each case is positive for the translocation characteristic of follicle center lymphoma.

tected only in the FCL component (in frozen sections; 3, 6).

Our immunohistochemistry results confirm that these two components are immunophenotypically distinct. The FCL cells expressed CD20, bcl-2, bcl-6,

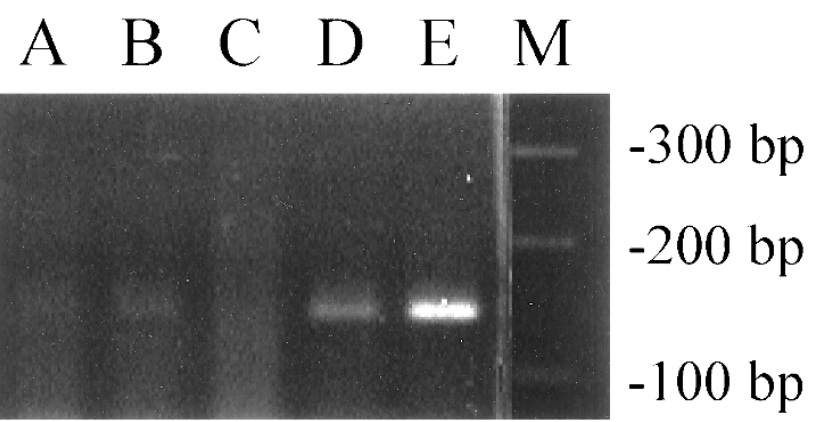

FIGURE 4. Case 1 polymerase chain reaction for $\mathrm{t}(14 ; 18)$ using major breakpoint region primers. $\boldsymbol{A}, 1 \%$ follicle center lymphoma tissue (derived from microdissected follicles of Case 1) diluted in 99\% reactive tonsil tissue (microdissected benign follicles); $\boldsymbol{B}, 10 \%$ follicle center lymphoma tissue (derived from microdissected follicles of Case 1) diluted in 90\% reactive tonsil tissue (microdissected benign follicles); $\boldsymbol{C}$, $100 \%$ reactive tonsillar tissue; $\boldsymbol{D}, 100 \%$ microdissected marginal-zone component; $\boldsymbol{E}, 100 \%$ microdissected follicular component; $\boldsymbol{M}$, marker lane. Strong bands are seen in Lanes $\boldsymbol{D}$ and $\boldsymbol{E}$. A faint band, significantly weaker than $\boldsymbol{D}$ and $\boldsymbol{E}$, is seen in Lane $\boldsymbol{B}$. Lanes $\boldsymbol{A}$ and $\boldsymbol{C}$ are negative. Ethidium bromide-stained polyacrylamide gel electrophoresis under ultraviolet light. 


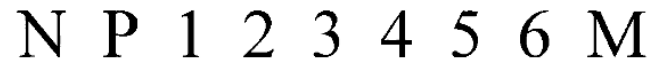

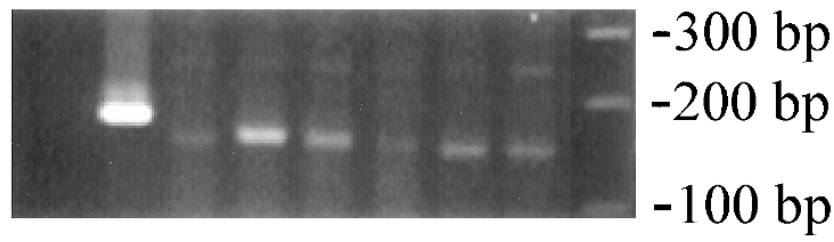

FIGURE 5. PCR for $\mathrm{t}(14 ; 18)$ of DNA from microdissected tissue from Cases 2 and 3. $\boldsymbol{n}$, negative control; $\boldsymbol{P}$, positive control. Lanes 2, 3 and Lanes 5, 6 are follicle center lymphoma and marginal-zone microdissected components of Cases 2 and 3, respectively. Lanes 1 and 4 are $5 \%$ microdissected follicles diluted in $95 \%$ microdissected reactive follicles from hyperplastic tonsil from Cases 2 and 3, respectively. A very faint band is seen at the $5 \%$ level, with much more intense bands seen in the corresponding follicle center lymphoma and marginal-zone lanes.

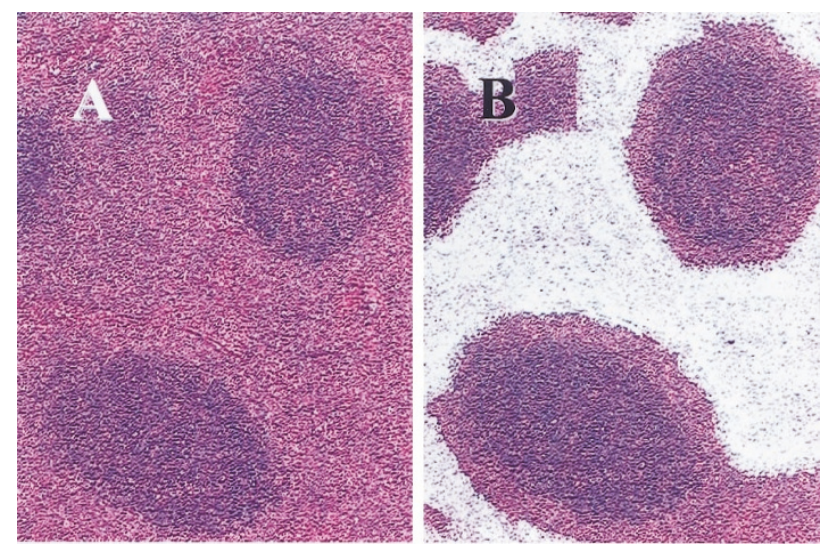

FIGURE 6. Example of before (A) and after (B) microdissection of the marginal zone component, Case 1.

and CD10, the characteristic phenotype of FCL. In contrast, the marginal-zone cells expressed CD20 and bcl-2 but not bcl-6 and CD10. Thus, immunophenotypically, they are similar to MZL (13). This immunophenotypic difference between the follicular and interfollicular B cells of FCL is similar to the findings of Dogan et al. (14) These authors found that FCL contains clonally linked but phenotypically distinct neoplastic B cells in the interfollicular region and suggested that there is active traffic between the two areas (14). It was not stated in their study whether any of the cases showed significant marginal-zone differentiation as in our current three cases. In our cases of FCL with marginal-zone components, the morphology as well as the phenotype were quite distinct.

We found identically sized bcl-2 PCR products in both components. Although sequencing was not performed, this strongly suggests a clonal identity, particularly in light of previous reports (2-4). The intensity of the band derived from the marginalzone component appeared stronger than that of a $5 \%-10 \%$ sensitivity control. This argues against contamination by rare cells from the follicular structures during microdissection and PCR. Thus, we confirm that FCL with marginal-zone component can be considered to be a single lymphoma with distinct morphologic and immunophenotypic components. This is in contrast to some other composite low-grade B-cell lymphomas with two immunophenotypically distinct cell populations, which are true biclonal lymphomas (15). Interestingly, a recent report in abstract form demonstrated findings similar to our own. Clonal rearrangements of identical size (IgH PCR) and major breakpoint region/JH DNA fusion sequences of identical band size and/or melting temperatures were detected in both components (16). As fluorescent in situ hybridization protocols and probes become more readily available, fluorescent in situ hybridization in intact paraffin sections could be performed to demonstrate the $t(14 ; 18)$ in the various cellular components.

In summary, by using immunohistochemistry and LCM/PCR, we demonstrate that FCL with a marginal-zone component shows different immunophenotypic profiles in each component. However, both components harbor the same bcl-2/IgH translocation. This report also emphasizes the fact that immunophenotypic and morphologic differences alone cannot be used to infer different clonal origin. The clinical significance of this type of lymphoma is uncertain, although a recent report suggests a worse clinical course compared with standard FCL (5). Additional descriptions will be needed to confirm an adverse clinical outcome, establish uniform criteria for diagnosis, and determine the amount of marginal zone differentiation that is clinically significant.

\section{Note in Proof}

During the review process for this manuscript, two studies of FCLs with monocytoid B-cell proliferations appeared. Abou-Elella et al. (17) published a study of four cases of follicle center lymphoma with monocytoid B-cell components and demonstrated identical clones in both the follicle center cells and MBC using microdissection and immunoglobulin heavy-chain gene polymerase chain reaction. Robetorye and colleagues (18) showed similar findings in three of four cases. As in our study identical bcl-2/IgH translocations were also found. These studies also confirm that the cells of both components are clonally related and harbor the bcl-2/IgH translocation.

Acknowledgments: The authors thank the technologists in the Cleveland Clinic Molecular Pathology Laboratory for their technical assistance. 


\section{REFERENCES}

1. Harris NL, Jaffe ES, Stein H, et al. A revised EuropeanAmerican classification of lymphoid neoplasms: a proposal from the International Lymphoma Study Group. Blood 1994; 84:1361-92.

2. Hernandez AM, Nathwani BN, Nguyen D, et al. Nodal benign and malignant monocytoid B cells with and without follicular lymphomas: a comparative study of follicular colonization, light chain restriction, bcl-2, and $\mathrm{t}(14 ; 18)$ in 39 cases. Hum Pathol 1995;26:625-32.

3. Schmid U, Cogliatti SB, Diss TC, et al. Monocytoid/marginal zone B-cell differentiation in follicle centre cell lymphoma. Histopathology 1996;29:201-8.

4. Mollejo M, Menarguez J, Cristobal E, et al. Monocytoid B cells. A comparative clinical pathological study of their distribution in different types of low-grade lymphomas. Am J Surg Pathol 1994;18:1131-9.

5. Nathwani BN, Anderson JR, Armitage JO, et al. Clinical significance of follicular lymphoma with monocytoid B cells. Non-Hodgkin's Lymphoma Classification Project. Hum Pathol 1999;30:263-8.

6. Slovak ML, Weiss LM, Nathwani BN, et al. Cytogenetic studies of composite lymphomas: monocytoid B-cell lymphoma and other B-cell non-Hodgkin's lymphomas. Hum Pathol 1993;24:1086-94.

7. Yang B, Tubbs RR, Finn W, et al. Clinicopathologic reassessment of primary cutaneous B-cell lymphomas with immunophenotypic and molecular genetic characterization. Am J Surg Pathol 2000;24:694-702.

8. Mann RB, Berard CW. Criteria for the cytologic subclassification of follicular lymphomas: a proposed alternative method. Hematol Oncol 1983;1:187-192.

9. Burton MP, Schneider BG, Brown R, et al. Comparison of histologic stains for use in PCR analysis of microdissected, paraffin-embedded tissues. Biotechniques 1998;24:86-92.
10. Sheibani K, Burke JS, Swartz WG, et al. Monocytoid B-cell lymphoma. Clinicopathologic study of 21 cases of a unique type of low-grade lymphoma. Cancer 1988;62:1531-8.

11. Ngan BY, Warnke RA, Wilson M, et al. Monocytoid B-cell lymphoma: a study of 36 cases. Hum Pathol 1991;22:409-21.

12. Nathwani BN, Mohrmann RL, Brynes RK, et al. Monocytoid B-cell lymphomas: an assessment of diagnostic criteria and a perspective on histogenesis. Hum Pathol 1992;23:1061-71.

13. Lai R, Arber DA, Chang KL, et al. Frequency of bcl-2 expression in non-Hodgkin's lymphoma: a study of 778 cases with comparison of marginal zone lymphoma and monocytoid B-cell hyperplasia. Mod Pathol 1998;11:864-9.

14. Dogan A, Du MQ, Aiello A, et al. Follicular lymphomas contain a clonally linked but phenotypically distinct neoplastic B-cell population in the interfollicular zone. Blood 1998;91:4708-14.

15. Fend F, Quintanilla-Martinez L, Kumar S, et al. Composite low grade B-cell lymphomas with two immunophenotypically distinct cell populations are true biclonal lymphomas. A molecular analysis using laser capture microdissection. Am J Pathol 1999;154:1857-66.

16. Robertorye R, Bohling SD, Medeiros LJ, Elenitoba-Johnson KSJ. Follicular lymphoma with monocytoid B-cell proliferation: molecular assessment of the clonal relationship between the follicular (F) and monocytoid B-cell (MBC) components. Mod Pathol 2000;13:161A.

17. Abou-Elella A, Shafer MT, Wan XY, Velanker M, Weisenburger DD, Nathwani BN, et al. Lymphomas with follicular and monocytoid B-cell components. Evidence for a common clonal origin from follicle center cells. Am J Clin Pathol 2000;114:516-22.

18. Robetorye RS, Bohling SD, Medeiros LJ, Elenitoba-Johnson KSJ. Follicular lymphoma with monocytoid B-cell proliferation: molecular assessment of the clonal relationship between the follicular and monocytoid B-cell components. Lab Invest 2000;80:1593-9. 